\title{
The burden of mental health illnesses in Kerala: a secondary analysis of reported data from 2002 to 2018
}

\author{
Jaison Joseph ${ }^{1 *}$ (10, D. Hari Sankar ${ }^{1}$ (1) and Devaki Nambiar ${ }^{1,2,3}$ (1)
}

\begin{abstract}
Background: The burden of mental health in India, as in other Low- and Middle-Income Countries (LMICS), is substantial. Secondary Analysis of survey data provides insight into trends in mental health morbidity over time, while administrative data can indicate corresponding trends in availability of infrastructure and services. We compared data from three national level surveys conducted in India to analyse trends in mental health morbidity and available institutional mechanisms to address mental health needs in Kerala, a south Indian state.
\end{abstract}

Methods: We compiled data from national and state level population surveys which reported mental health morbidity from 2002 to 2018. We compared the prevalence of mental health illness and disability reported in Kerala with national estimates. We also mapped the most recently available health human resource and infrastructure available in Kerala for mental health care. Basic descriptive statistics were computed for both sets of indicators using Microsoft Excel.

Results: In 2002, Kerala had 194 persons per hundred thousand population with mental retardation and intellectual disability which increased to 300 persons per hundred thousand population in 2018. The number of individuals with mental health illness in the state increased from 272 person per hundred thousand to 400 persons per hundred thousand in the time period of 2002 to 2018. There were 5.53 beds available per ten thousand persons for treatment in Kerala in 2018.

Conclusion: Kerala experienced a rapid rise in mental health morbidity between 2002 and 2018. The most recently reported health human resource and infrastructure availability in the state appears to be inadequate to cater to the requirements of mental health care, even as improvements and upgradations are underway. Service and system design changes will have to be mapped and evaluated over time.

Keywords: Mental health, Disability, Surveys, Primary health, Mental health care, Kerala

\section{Background}

Mental disorders account for the second highest number of Years lived with disability (YLDs) and represent the sixth leading burden in Disability-Adjusted Life Years (DALYs) in the world in 2017 [1]. They also place an

\footnotetext{
*Correspondence: jjoseph@georgeinstitute.org.in; jaison123127@gmail.com

${ }^{1}$ The George Institute for Global Health, 308, Third Floor, Elegance Tower,

Plot No. 8, Jasola District Centre, New Delhi 110025, India

Full list of author information is available at the end of the article
}

enormous economic burden on individuals and societies [2]. A 2016 study on disease burden due to mental disorders by the Indian Council of Medical Research (ICMR) found that one in seven persons in India suffered from mental disorders of varying severity; depression, affecting 45.7 million people, and anxiety disorders, affecting 44.9 million, were the most common [1]. There has been a welcome transformation in the perception of mental illness over the past several decades; with due recognition 
of the need to safeguard mental health and well-being given in the Sustainable Development Goals (SDGs) [3]. The World Health Organization in its special initiative for mental health (2019-2023) advocated for the inclusion of mental health in the universal health coverage agenda; adding that mental health policies premised on human rights principles should be in place, alongside scaled-up mental health interventions and services at the primary level upwards [4].

Studies show that the prevalence of mental disorders is high among adults in the southern states of India; the burden is concentrated among children and adolescents in the northern states $[1,5]$. As per the 2016 Global Disease Burden (GBD) profile of the southern Indian state of Kerala, suicide and violence were among the top 10 causes of death in the $0-14$ age group (1.4\%), 15-39 age group (24.4\%) and 40-69years (3.9\%) [6]. Among the top 15 causes of Years of Life Lost (YLLs) in 2016, suicide ranked third among both male and females. More broadly, the state is facing several challenges due to high morbidity and mortality arising out of the dual burden of communicable and non-communicable diseases, in a population comprised of a growing ageing population, high rates of out migration, and alcohol use [7]. Studies have shown that these factors are associated with mental health disorders $[1,5]$.

The Kerala state report of the National Mental Health Survey, 2015-16 reported an overall prevalence of any mental disorders of $11.36 \%$ [7]. Prevalence of common mental disorders and severe mental disorders were 11 and $0.44 \%$ respectively [7]. In 2014 The National Crime Records Bureau (NCRB) estimated that the proportion of persons with high risk of suicidality in Kerala was 2.23\% [7]. In 2018 the NCRB reported that the overall incidence rate of suicide per 100,000 persons in Kerala was 23.5, which is double the national rate [8]. The Kerala Disability Census 2015 reported that $8.66 \%$ of households in the state had persons with disabilities and 232 persons per 10,000 population suffered from either mental or physical disabilities. Among the total persons with disabilities $(7,93,937) \quad 12.72 \%$ reported mental illness, $8.68 \%$ were persons with intellectual disability, and $0.804 \%$ had Cerebral palsy [9].

Studies have examined the point prevalence of mental health disabilities in the state $[1,10-12]$. The lack of epidemiological and community-based surveys analysing risk factors and documenting the impact of interventions is a major constraint to understanding mental health challenges in the state [13], particularly over time. While raw survey data could allow some exploration of this, changing diagnostic criteria, differences in assessment and instrumentation and reporting across surveys make it difficult to compare across years and make inferences about trends related to mental health disorders [14]. Yet, there are some surveys that can be used to look at trends, which is what our analysis placed emphasis on.

In terms of policy and programmatic responses to address the aforementioned burdens, superseding the Mental Health Act of 1987, India's Mental Health Act, 2017 focussed on safeguarding the rights of the people with mental illness, along with access to healthcare and treatment without discrimination from the government [15]. Kerala was among the first in the country to establish a Mental Health Policy in 2003, which was revised in 2013 [7]. It has a district mental health programme functional across all the 14 districts as per the guidelines of National Mental Health Programme (1996) and has shown innovation in policy development and implementation for the care of people with mental health needs $[16,17]$. Despite these efforts, the state still has treatment gaps and losses to follow up among those seeking services for mental health disorders in the state $[12,18]$.

Kerala is not unique here; India's National Mental Health Survey indicates that mental healthcare services have several underperforming components clubbed with the lack of a comprehensive overall strategy [19]. A strong and effective public health infrastructure can not only to respond to crises but is able to appropriately address the continuum of mental health care needs - preventive, promotive and curative [20, 21]. Globally, in 2014-2016, the median number of beds per 100,000 population requiring mental health inpatient care ranged from below 7 in Low and Middle Income Countries (LMICs) to over 50 in High Income Countries (HICs); the availability of outpatient services was almost 30 times lower in the LMICs as compared to HICs [22]. During this period in India, the availability of beds for mental health in general hospitals per 100,000 population was 0.560 , in community residential facilities was 5.178 and in mental hospitals, 1.426 [23]. It is unclear how this availability corresponded to actual burden; this is what our analysis sought to do.

Mental health services rely on the competence and motivation of a skilled workforce [24]. One psychiatrist per 100,000 population is recommended in the Indian scenario by the National Institute of Mental Health and Neuro-Sciences (NIMHANS) [25]. But in 2014, India had only 0.3 psychiatrists per 100,000 population [26]. The median number of psychiatrists in 2017 in the country was only 0.2 compared to global median of 3 per 100,000 population, with similarly low availability of psychologists $(0.03$ per 100,000$)$, social workers $(0.03$ per 100,000$)$ and nurses $(0.05$ per 100,000$)$ available for mental health care [27]. Considering Kerala's disproportionate burden, it is critical to understand what the availability of these human resources is in the state. 
The aim of the current study was to focus on comparable measures available from three large-scale surveys in India to explore a) trends in the prevalence of mental health disorders in Kerala across data sources and b) health infrastructure and human resource available for mental health care reported through national and state surveys.

\section{Methods}

We identified data sources through desk review of largescale health surveys that reported on mental health between 2002 and 2018. We shortlisted six national level surveys of which three were found suitable for comparison as they had nationally representative samples and have been used by government agencies for formulating policy decisions. We analysed the indicators and definitions that could be used for comparison across the years. While routine data is gathered on a number of indicators, including mental health services, reporting quality has been found to be poor [28]. The data sources used to determine prevalence were the National Sample Survey Office (NSSO) Survey on Disability in its 58th (July - December 2002) and 76th (July - December 2018) rounds and the Census of India 2011. The detailed methodology for each of these studies is mentioned elsewhere $[11,29,30]$; to summarise, the 58th and 76th rounds employed two-stage stratified, random cluster sampling (separately for urban and rural households) with the former round relying on the 2001 Census (excluding geographically remote villages in Jammu \& Kashmir, Nagaland, and Andaman and Nicobar Islands) and the latter on the 2011 Census (excluding remote villages in the Andaman and Nicobar Islands). The 2011 Census employed population enumeration in 35 states and Union Territories of the country, in the course of which information on disability was included. More detail on the sampling frame and indicators used in this analysis is provided in supplementary file 1 . The 2015-16 National Mental Health Survey report was used to assess the availability of health infrastructure and human resource for mental health care in Kerala; this study design was multi-stage, stratified, random cluster sampling, with random selection of households based on Probability Proportionate to Size (PPS) across stages [7].

Units of measurement reporting mental retardation/ intellectual disability and mental illness were standardized to NSS 58th round unit measurements. The NSS 58th round reported number of persons with mental retardation and mental illness per 100,000 population whereas Census 2011 reported number of persons by type of disability and NSS 76th round reported percentage of persons with mental disabilities. The population of Kerala as per Census 2011 population [31] and projected population for 2017 were used for estimations [32]. Human resource and infrastructure data were standardized, and the availability per 10,000 population were assessed, as per World Health Organization (WHO) recommendations [33] .

\section{Results}

Burden of mental disorders in Kerala

The 2002 NSS 58th round reported 94 persons per 100,000 with intellectual disability; and 105 persons per 100,000 for the mentally ill nationally, whereas in Kerala the figures were 194 and 272 persons per 100,000, respectively. In Kerala, the prevalence of both indicators was higher among males (intellectual disability: 234 per 100,000 males; mental illness: 282 per 100,000 population) as compared to females (intellectual disability: 160 per 100,000 population; and mental illness: 263 per 100,000 population).

Census 2011 data showed that 140 persons per 100,000 population in Kerala had intellectual disability when compared with the Indian average of 124 persons. Similarly, persons with mental illness per 100,000 population was approximately three times higher in Kerala when compared with the national average. NSS 76th round data (from 2018) showed higher burden of intellectual disability and mental illness in Kerala calculated in person per 100,000 when compared with the national average (see Table 1).

Table 1 Number of persons with mental retardation and mental illness per 100,000 population from 2002 to 2018

\begin{tabular}{|c|c|c|c|c|c|c|c|c|c|c|c|c|}
\hline \multirow[t]{3}{*}{ Source of Data } & \multicolumn{6}{|c|}{ Mental retardation/Intellectual Disability } & \multicolumn{6}{|c|}{ Mental illness } \\
\hline & \multicolumn{3}{|c|}{ Kerala } & \multicolumn{3}{|l|}{ India } & \multicolumn{3}{|c|}{ Kerala } & \multicolumn{3}{|l|}{ India } \\
\hline & Male & Female & Person & Male & Female & Person & Male & Female & Person & Male & Female & Person \\
\hline NSS 58th 2002 & 234 & 160 & 194 & 115 & 72 & 94 & 282 & 263 & 272 & 122 & 86 & 105 \\
\hline Census 2011 & 215 & 168 & 191 & 140 & 108 & 124 & 205 & 185 & 194 & 67 & 52 & 60 \\
\hline NSS 76th 2018 & 400 & 300 & 300 & 200 & 200 & 200 & 400 & 400 & 400 & 100 & 100 & 100 \\
\hline
\end{tabular}

Source: Compiled by authors from NSS 58th round [29], Census of India 2011 [30], NSS 76th round [11] 


\section{Infrastructure and human resources available for mental health care}

As per the most recently available data from 2015 to 16 , the availability of mental health care hospitals in the state was less than 0.001 per 10,000 population (see Table 2). The availability of beds for inpatient care was 0.569 per 10,000 population. Only $22 \%(N=7)$ of the medical colleges in the state offered psychiatric care. Further, 0.023 sub-district hospitals per 10,000 population provided outpatient/inpatient services for mental health care, whereas none of the primary health care facilities in the reference period could be said to formally deliver care for mental health.

Comparison of Kerala's human resource for mental health (see Table 3) data with national average and estimated requirement showed that the state currently possess 400 psychiatrists, representing a coverage of 0.12 per 10,000 population which is better than national average
(0.067 per 10,000 population), but falls short of recommended coverage of the mental health workforce in India [35]. This pattern is consistent with data on other human resources for mental health like clinical psychologists, but the availability of psychiatric social workers in Kerala was less than national and very low when compared to the estimated requirement.

\section{Discussion}

We examined summary trends in prevalence of mental health conditions from 2002 to 2018 reported in nationally representative surveys and the latest status of mental health service delivery infrastructure and human resources coverage in the state of Kerala. Overall, we found that burden was greater in Kerala as compared to national averages and has been steadily growing. We also found that the availability of infrastructure and health workers falls short of globally recommended thresholds.

Table 2 Availability of Health facilities Available for Mental Health Care in the State

\begin{tabular}{|c|c|c|}
\hline Facility Type & Number & $\begin{array}{l}\text { Availability } \\
\text { per } 10,000 \\
\text { population }\end{array}$ \\
\hline Mental hospitals & 3 & 0.001 \\
\hline${ }^{a}$ Medical colleges with psychiatric department & 7 & 0.002 \\
\hline General hospitals with psychiatric unit & 18 & 0.005 \\
\hline Sub district hospital providing OP/IP for mental health & 79 & 0.023 \\
\hline Primary health facilities providing OP for mental health & 0 & 0 \\
\hline Beds available for mental health inpatient services & 1962 & 0.569 \\
\hline Mobile mental health units & 22 & 0.006 \\
\hline Day care centres & 43 & 0.012 \\
\hline Vocational training centres & 10 & 0.003 \\
\hline Sheltered workshops & 6 & 0.002 \\
\hline Long stay homes & 146 & 0.042 \\
\hline
\end{tabular}

${ }^{a}$ Information pertains to both public and private health care facilities

Source: Health at a glance, DHS Kerala [34], National Mental Health Survey, Kerala report 2015-16

Table 3 Human Resources available for Mental Health Care in Kerala and India

\begin{tabular}{|c|c|c|c|c|c|}
\hline \multirow[t]{2}{*}{ Type } & \multicolumn{2}{|l|}{ Kerala } & \multicolumn{2}{|l|}{ India } & \multirow{2}{*}{$\begin{array}{l}\text { Requirement per } \\
10,000 \text { population }\end{array}$} \\
\hline & $\begin{array}{l}\text { Number of Health } \\
\text { Workers }\end{array}$ & $\begin{array}{l}\text { Availability per } 10,000 \\
\text { population }\end{array}$ & $\begin{array}{l}\text { Number of Health } \\
\text { Workers }\end{array}$ & $\begin{array}{l}\text { Availability per } 10,000 \\
\text { population }\end{array}$ & \\
\hline Psychiatrist & 400 & 0.12 & 9000 & 0.067 & 3 \\
\hline Clinical psychologist & 211 & 0.06 & 1000 & 0.007 & 3 \\
\hline Psychiatric Social workers & 15 & 0.004 & 1000 & 0.007 & 3 \\
\hline $\begin{array}{l}\text { Rehabilitation workers and spe- } \\
\text { cial education teachers }\end{array}$ & 3429 & 1 & 2649 & 0.020 & 3 \\
\hline $\begin{array}{l}\text { Nurses with Diploma in Psychi- } \\
\text { atric Nursing }\end{array}$ & 0 & 0 & 2000 & 0.015 & 3 \\
\hline
\end{tabular}

Estimations for mental health workforce by Garg et. al for India based on Global Mental Health Norms [35]

Source: National Mental Health Survey, Kerala report 2015-16 
A third of patients seeking care in community based or psychiatric hospital setting have been reported to experience internalised stigma [36]. Even accounting for under-reporting in surveys assessing mental disability, prevalence is increasing. Indeed, actual burden may be higher in Kerala, but is the level of health literacy and health seeking in the state, in a larger context where emphasis is being placed on reporting on this issue. This is a clear area for further study. Studies have attributed the rise of depression in Kerala to a shift in family patterns from joint to nuclear families and the associated rise in loneliness and abandonment of the elderly, rising divorce rates, unemployment, gender inequalities, economic migration to countries in the Middle East/Gulf region (with wives staying behind in Kerala), overconsumption, pressure on students, alcoholism, and tensions associated with modern living [17, 37]. National Crime Records Bureau (NCRB) data from 2016 report that family problems, illness, alcohol/ drug abuse and bankruptcy are also major drivers of suicide in India [38]. Clearly, more study is needed in this domain.

Having been the first Indian state to formulate a mental health policy (in 2003), Kerala has been expanding services in order to offer screening and management of common mental health conditions at the primary health care level [39]. In 1999 the District Mental Health Programme (DMHP), and Direct Intervention System for Health Awareness (DISHA) released in 2013 were designed to strategize around and implement mental health initiatives by expanding the district mental health program and integrating it with the private sector [40]. Alongside this, strong referral pathways have to be established to provide more specialised care for mental health [41]. These programmatic aspects need to be assessed and evaluated.

Studies have indicated a lack of mental health service provision in primary health centres in the state [40, 42]. This is now expected to change given the reforms brought about under the aegis of Kerala's Aardram flagship initiative, which established depression screening clinics named Ashwas (which roughly translates into "assurance") (initially) in nearly 170 Family Health Centres (FHCs) across the state. Ashwas doctors and staff nurses are trained in psycho-social counselling and clinical guidelines, and are directed to manage screening for depression and treatment at FHCs, while trained field health workers are to identify cases in defined vulnerable and high risk groups for referral to FHCs [43]. The degree to which this program can improve diagnosis, treatment and care of those with mental health conditions is a critical area for further monitoring and research. The DHMP and Ashwas clinics are joined by the private sector in providing services in the face of continued calls for improved accessibility, availability, and quality of mental health services and family-support services for this target population [40, 44, 45]. This is another area of further study.

Delivery of services for mental health depends on the availability of human resources for providing such services. India has a long way to go in this area: a $2011 \mathrm{WHO}$ report found that for every million people in India, there are just three psychiatrists, and even fewer psychologists, 18 times fewer than the Commonwealth norm of 5.6 psychiatrists per 100,000 people [46]. In Kerala, the number of psychiatrists available per thousand population was higher than the Indian average, however there were relatively fewer clinical psychologist, psychiatric social workers and no psychiatric nurses available in the state. The shortage of mental health professionals is especially acute in the public sector [42]. An assessment conducted in 2013 found that district level shortages abound; $75 \%$ of psychiatrist positions were found to be vacant in Malappuram and Palakkad districts [47]. This has been tied to medical education; Roy and Rasheed found a deficiency in the number of psychiatry post graduate seats, attributing this to the inadequate number of psychiatrists in the country [25]. These shortages can be addressed with appropriate training for health care professionals at the primary level [48] as well as non-specialist health-care providers [12].

The toll of COVID-19 on mental health is well established [49]: globally, around three fourths of COVIDaffected persons have been diagnosed with posttraumatic stress disorders (PTSD) along with depressive and anxiety disorders [50]. Studies have found that health providers are facing stress, anxiety, depressive symptoms, insomnia, denial, anger and fear due to social isolation $[51,52]$. People in quarantine have reportedly experienced boredom, loneliness, anger, anxiety and guilt about the effect of contagion and stigma on family and friends $[52,53]$. A recent study found that during the COVID19 pandemic in Kerala, depression was a major problem faced by people under home quarantine $(75.2 \%)$ followed by stigma $(69.5 \%)$ and anxiety $(69.4 \%)$ [54]. In response, the state adopted inter and intra-departmental coordination to ensure continuity of services and access to additional support like medications and rations - in part to mitigate these challenges [52]. Clearly more is needed: COVID has starkly revealed that both Kerala and India are indicative of the phenomenon common in Low and Middle Income Countries (LMICs), where despite substantial and growing burdens, support for mental health and psychological care is vitiated by scarcity of resources and lack of adequate information in the population [41]. Research and programmatic support are required to strengthen these responses. 


\section{Limitations}

Despite the similarity of domains analysed, the scale of measurement differed for most of the surveys. Some reported in percentages, others in proportions and some in absolute numbers, which raised issues of comparability across the years. The focus of mental health surveys has also varied over the years and now perception of mental illness has changed resulting in change of operational definitions, again limiting comparability over the years. Ideally, secondary data would be triangulated across multiple data sources to improve quality and ensure reliability [55]. This is of course difficult to do with survey data, which is of long periodicity typically, and tends not to afford such comparison or triangulation. Often, routine health data can be used for this purpose. In our case, however, routinely collected departmental data on mental health illness in the state was not available in the public domain. A report by NITI Aayog, a premier think tank of the Indian government, has also raised concern that routinely collected data in our public health system has quality issues (like incompleteness and lack of validation) [56]. Another limitation in our analysis was our inability to look at population subgroups facing greater burdens of mental illness. Future research should draw from across sources to carry out more precise and triangulated analyses, adjusting for age, sex, as well as other dimensions of inequality, such as socio-economic status, occupation, and more.

\section{Conclusion}

There appears to be a substantial increase in mental health illness over the 16-year study period in the state of Kerala. The current health infrastructure in the public sector of the state has so far been inadequate to meet the current burden of the problem and to ensure universal health coverage to its population. Kerala's increased emphasis on mental health as per recent reforms is a welcome change and should be monitored using standardised definitions in both routine health information systems and large population-based surveys, enabling comparability over time.

\footnotetext{
Abbreviations

DALYs: Disability Adjusted Life Years; DMHP: District Mental Health Programme; DISHA: Direct Intervention System for Health Awareness; FSUs: Sample First Stage Units; ICMR: Indian Council of Medical Research; LMICs: Low- And Middle-Income Countries; NCRB: National Crime Records Bureau; NIMHANS : National Institute of Mental Health and Neurosciences; NITI: National Institution for Transforming India; NMHS : National Mental Health Survey; NSS: National Sample Survey; NSSO: National Sample Survey Office; ORGCS: Office of Registrar General and Census Commissioner; PTSD: Posttraumatic Stress Disorders; PWD Act: Persons with Disabilities Act; SDG: Sustainable Development Goal; SDH: Sub District Hospital; SDI: Socio-Demographic Index; WHO:
}

World Health Organization; YLDs: Years Lived with Disability; YLLs: Years of Life Lost.

\section{Supplementary Information}

The online version contains supplementary material available at https://doi. org/10.1186/s12889-021-12289-0.

Additional file 1. Methodology and Indicators for Analysis.

\section{Acknowledgements}

Not applicable.

\section{Authors' contributions}

Conceptualization: JJ; Methodology: JJ, HS, DN; Formal analysis and investigation: JJ; Writing - original draft preparation: JJ, HS; Writing - review and editing: JJ, HS, DN; Funding acquisition: DN; Supervision: DN; We confirm that the manuscript has been read and approved by all named authors and that there are no other persons who satisfied the criteria for authorship but are not listed. We further confirm that the order of authors listed in the manuscript has been approved by all of us.

\section{Funding}

We wish to indicate that this work was supported by the Wellcome Trust/DBT India Alliance Fellowship (https://www.indiaalliance.org) Grant number IA CPHI/16/1/502653) awarded to Dr. Devaki Nambiar. The funder had no role in study design, data collection and analysis, decision to publish, or preparation of the manuscript. The funder provided support in the form of salaries and research materials for authors Devaki Nambiar (DN), Hari Sankar D (HS) and Jaison Joseph $(\mathrm{JJ})$ but did not have any additional role in the study design, data collection and analysis, decision to publish, or preparation of the manuscript. The specific roles of these authors are articulated in the 'author contributions' section.

\section{Availability of data and materials}

All data collected and analysed during this study are sourced from data sources available in the public domain and the links to these sources are given below. The data management and analysis plan are detailed in method section and the supplementary information files. These sources are open to access as on 28th October 202

Data source 1: Disabled persons in India - NSSO 58th round available from http://www.icssrdataservice.in/datarepository/index.php/catalog/69/downl $\mathrm{oad} / 877$.

Data source 2: Disabled persons in India a statistical profile 2016 available from http://mospi.nic.in/sites/default/files/publication_reports/Disabled_persons_ in_India_2016.pdf.

Data source 3: Persons with disabilities in India- NSSO 76th round available from http://mospi.nic.in/sites/default/files/publication_reports/Report_583_ Final_0.pdf.

Data source 4: Health at a glance 2018 available from https://dhs.kerala.gov.in/ wp-content/uploads/2020/03/health_25022019.pdf.

Data source 5: National mental health survey of India 2015-16 Kerala report available from http://indianmhs.nimhans.ac.in/Docs/statereports/KeralaNMHS-Report.pdf.

\section{Declarations}

Ethics approval and consent to participate

This is review of secondary data available in the public domain hence ethical approval not required.

\section{Consent for publication}

Not applicable.

\section{Competing interests}

We are in full adherence of BMC Public Health policies on sharing data and materials. I wish to confirm that all authors have no competing interests to declare. 


\section{Author details}

'The George Institute for Global Health, 308, Third Floor, Elegance Tower, Plot No. 8, Jasola District Centre, New Delhi 110025, India. ${ }^{2}$ Prasanna School of Public Health, Manipal Academy of Higher Education, Manipal, India. ${ }^{3}$ Faculty of Medicine, University of New South Wales, Sydney, Australia.

Received: 6 April 2021 Accepted: 22 November 2021 Published online: 11 December 2021

\section{References}

1. Sagar R, Dandona R, Gururaj G, Dhaliwal RS, Singh A, Ferrari A, et al. The burden of mental disorders across the states of India: the Global Burden of Disease Study 1990-2017. Lancet Psychiatry. 2020;7(2):148-61.

2. World Health Organization, Noncommunicable Disease and Mental Health Cluster. Investing in mental health. Geneva: World Health Organization; 2003.

3. World Health Organization. Mental health included in the UN sustainable development goals: WHO. World Health Organization; 2020. [cited 2021 Mar 7]. Available from: http://www.who.int/mental_health/SDGs/en/

4. World Health Organization. Special initiative for mental health (20192023). Geneva: World Health Organization. 2019. p. 4. https://www.who. int/publications/i/item/special-initiative-for-mental-health-(2019-2023).

5. Murthy RS. National Mental Health Survey of India 2015-2016. Indian J Psychiatry. 2017;59(1):21-6.

6. India: Health of the Nation's States The India State-Level Disease Burden Initiative. Indian Council Of Medical Research, Public Health Foundation of India, Institute for Health Metrics and Evaluation; 2016 [cited $2020 \mathrm{Apr}$ 17]. Available from: https://www.healthdata.org/sites/default/files/files/ policy_report/2017/India_Health_of_the_Nation\%27s_States_Report_ 2017.pdf

7. Shibukumar, Thavody J, National Mental Health Survey of India, 2015-16. Kerala State Report. Kozhikode: IMHANS; 2017.

8. National Crimes Records Bureau. Accidental Deaths \& Suicides in India. 2018 [cited 2021 Aug 29]. Available from: https://ncrb.gov.in/sites/defau It/files/chapter-2-suicides-2018.pdf

9. Kerala Disability Census Report. Social Security Mission, Government of Kerala; 2015. Available from: www.socialsecuritymission.gov.in/index.php. Accessed 7 Dec 2021

10. Babu AR, Sreedevi A, John A, Krishnapillai V. Prevalence and determinants of somatization and anxiety among adult women in an urban population in Kerala. Indian J Community Med. 2019;44(5):66.

11. Persons with Disabilities in India. Ministry of statistics and programme implementation, government of India; 2018.

12. Shaji KS, Raju D, Sathesh V, Krishnakumar P, Punnoose VP, Kiran PS, et al. Psychiatric morbidity in the community: a population based-study from Kerala. Indian J Psychiatry. 2017;59(2):149-56.

13. Doncy J. Eapen. Institutionalized children: the underprivileged. Int J Nurs Pract. 2009;15(5):349-52.

14. Collishaw S, Maughan B, Goodman R, Pickles A. Time trends in adolescent mental health: time trends in adolescent mental health. J Child Psychol Psychiatry. 2004;45(8):1350-62.

15. The Mental Healthcare Act. Ministry of Law and Justice, Government of India; 2017 [cited 2020 Apr 17]. Available from: https://www.prsindia. org/uploads/media/Mental\%20Health/Mental\%20Healthcare\%20Act,\% 202017.pdf

16. Shaji KS, Lal PK, Harish MT, Kishore NRA, Mohandas E. People's participation in mental health planning the Kerala initiative. Indian J Psychiatry. 2001;43(4):330-4

17. Lang C. Inspecting mental health: depression, surveillance and Care in Kerala, South India. Cult Med Psychiatry. 2019;43(4):596-612.

18. Praveenlal K. Policy and programmes for mental health in Kerala. BMC Proc. 2013;7(Suppl 5):012

19. National Mental Health Survey India. Ministry of Health and Family Welfare, Government of India; 2016 [cited 2020 Apr 17]. Available from: http://indianmhs.nimhans.ac.in/Docs/Report2.pdf

20. Kumar A, Gupta S. Health Infrastructure in India: Critical Analysis of Policy Gaps in the Indian Healthcare Delivery: Vivekananda International Foundation; 2012. [cited 2020 Apr 17]. Available from: https://www.vifin dia.org/sites/default/files/health-infrastructure-in-india-critical-analysisof-policy-gaps-in-the-indian-healthcare-delivery.pdf

21. Century, I. of M. (US) C. on A. the H. of the P. in the 21 st. The Governmental Public Health Infrastructure. In The Future of the Public's Health in the 21st Century. National Academies Press (US). 2002. https://www.ncbi.nlm. nih.gov/books/NBK221231/.

22. World Health Organization, World Health Organization. Mental health atlas 2017. Geneva: World Health Organization; 2018. p. 62.

23. Global Health Observatory. World health organization. World Health Organization; 2020 [cited 2020 Apr 17]. Available from: https://apps.who. int/gho/data/view.main.HSO7v

24. Human resources and training in mental health. Geneva: World Health Organization; 2005. 123 p. (Mental health policy and service guidance package).

25. Roy S, Rasheed N. The National Mental Health Programme of India, vol. $10 ; 2015$

26. World Health Organization. Mental Health Atlas: World Health Organization; 2014. [cited 2020 Apr 17]. Available from: http://www.who.int/ mental_health/evidence/atlas/mental_health_atlas_2014/en/

27. Math SB, Gowda GS, Basavaraju V, Manjunatha N, Kumar CN, Enara A, et al. Cost estimation for the implementation of the Mental Healthcare Act 2017. Indian J Psychiatry. 2019;61(Suppl 4):S650-9.

28. World Health Organization. 2005. Mental health information systems. Mental Health Policy and Service Guidance Package. (English). Geneva. Available from: https://www.who.int/mental_health/policy/mnh_info_ sys.pdfz.

29. Disabled Persons in India, NSS 58th Round [Internet]. National Sample Survey Organisation Ministry of Statistics and Programme Implementation Government of India; 2003 Dec. Available from: http://www.icssr dataservice.in/datarepository/index.php/catalog/69/download/877.

30. Disabled persons in India a Statistical Profile. Social Statistics Division, Ministry of Statistics and Programme Implementation; 2016.

31. Socio-Economic Caste Census-2011. [cited 2020 May 25]. Available from: https://secc.gov.in/statewiseGenderProfileReport?reportType=Gender\% 20Profile

32. Gender Statistic. Department of Economics and Statistics, Government of Kerala; 2017 [cited 2020 Aug 18]. Available from: http://www.ecostat. kerala.gov.in/images/pdf/publications/General_Publication/data/rep_ gender_stat_1718.pdf

33. Monitoring the Building Blocks of Health Systems: A Handbook of Indicators and their Measurement Strategies. World Health Organization; 2010 [cited 2020 Aug 18]. Available from: https://www.who.int/workforceallian ce/knowledge/toolkit/26.pdf

34. Health at a Glance 2018. [cited 2020 Aug 18]. Available from: https://dhs. kerala.gov.in/wp-content/uploads/2020/03/health_25022019.pdf

35. Garg K, Kumar CN, Chandra PS. Number of psychiatrists in India: baby steps forward, but a long way to go. Indian J Psychiatry. 2019;61(1):104-5.

36. James TT, Kutty VR. Assessment of internalized stigma among patients with mental disorders in Thiruvananthapuram District, Kerala, India. Asia Pac J Public Health. 2015;27(4):439-49.

37. Madore A, Rosenberg J, Dreisbach T, Weintraub R. Positive outlier: health outcomes in Kerala, India over time; 2018.

38. Accidental Deaths \& Suicides in India. National Crime Records Bureau 2019. p. 194-6. [cited 2020 Sep 11].Available from: https://ncrb.gov.in/ sites/default/files/Chapter-2-Suicides 2019.pdf

39. Transforming Primary Health Centres into Family Health Centres Guidelines. Health \& Family Welfare Department -; 2016 [cited 2020 Sep 11]. Available from: http://shsrc.kerala.gov.in/pdf/462017H\&FWD.pdf

40. Kumar MT. Mental health care: can we create a new Kerala model? vol. 9; 2015.

41. Chatterjee P. Providing psychosocial support in Kerala after the floods. Lancet. 2018:392(10154):1181-2.

42. DRV. Shaharban. Right to Health and Role of Mental Health Institutions in Kerala. 2018 [cited 2020 Apr 17]; Available from: https://www.researchga te.net/publication/324638063_Right_to_Health_and_Role_of_Mental_ Health Institutions in Kerala

43. 'Aashwasam' to tackle depression. The Hindu. 2017 Apr 8 [cited 2020 Jun 1]; Available from: https://www.thehindu.com/news/cities/Thiruvanan thapuram/aashwasam-to-tackle-depression/article17877055.ece 
44. Indu P, Remadevi S, Philip S, Mathew T. A qualitative study on the mental health needs of elderly in Kerala, South India. J Geriatr Ment Health. 2018;5(2):143

45. Prakash O, Kukreti P. State of geriatric mental health in India. Curr Tran Geriatr Gerontol Rep. 2013;2(1):1-6.

46. Mental Health Atlas. World Health Organization. World Health Organization; 2011 [cited 2020 Jun 1]. Available from: https://www.who.int/ mental_health/publications/mental_health_atlas_2011/en/

47. Nandraj S, Joseph J, Mannethodi K, Thankachy Y, Nambiar D, Shastri R, et al. God's own country moving towards universal health coverage in Kerala; 2016. p. 176.

48. Singh OP. District mental health program - need to look into strategies in the era of mental health care act, 2017 and moving beyond Bellary model. Indian J Psychiatry. 2018;60(2):163-4

49. The world health report, Mental Health: New Understanding, New Hope [Internet]. World Health Organization; 2001 [cited 2020 Apr 17]. Available from: https://www.who.int/whr/2001/en/

50. Murthy RS. Disaster mental health and social psychiatry: challenges and opportunities. Indian J Soc Psychiatry. 2018;34(4):323.

51. Kang L, Li Y, Hu S, Chen M, Yang C, Yang BX, et al. The mental health of medical workers in Wuhan, China dealing with the 2019 novel coronavirus. Lancet Psychiatry. 2020;7(3):e14.

52. John CE, Gunasekaran I, N RM. COVID-19: Taking Heed From Kerala's Mental Health Interventions. The Wire Science. 2020 [cited 2020 Apr 19]. Available from: https://science.thewire.in/health/ covid-19-kerala-mental-health/

53. Xiang Y-T, Yang Y, Li W, Zhang L, Zhang Q, Cheung T, et al. Timely mental health care for the 2019 novel coronavirus outbreak is urgently needed. Lancet Psychiatry. 2020;7(3):228-9.

54. Ravindran, R. M., Anjali Krishnan, R., Kiran, P. S., Mohan, B., \& Shinu, K. S. Psychosocial Intervention Model of Kerala, India During Pandemic COVID-19: "Ottakkalla Oppamundu (You're not alone, we're with you)." Int J of Health Serv. 2021b;51(4):436-45. https://doi.org/10.1177/0020731421 1019240.

55. Downey L, Rao N, Guinness L, Asaria M, Prinja S, Sinha A, et al. Identification of publicly available data sources to inform the conduct of health technology assessment in India. F1000Res. 2018;7:245.

56. Healthy States and Progressive India, Report on the Ranks of States and Union Territories. NITI Aayog; 2019 Jun [cited 2020 Apr 17]. Available from: http://social.niti.gov.in/uploads/sample/health_index_report.pdf

\section{Publisher's Note}

Springer Nature remains neutral with regard to jurisdictional claims in published maps and institutional affiliations.

Ready to submit your research? Choose BMC and benefit from:

- fast, convenient online submission

- thorough peer review by experienced researchers in your field

- rapid publication on acceptance

- support for research data, including large and complex data types

- gold Open Access which fosters wider collaboration and increased citations

- maximum visibility for your research: over $100 \mathrm{M}$ website views per year

At BMC, research is always in progress.

Learn more biomedcentral.com/submissions 